\title{
The Influence of CYP4F2 Polymorphisms on Warfarin Doses in Korean Patients with a Variety of Diseases
}

\author{
Jia Xin Li, ${ }^{1,2,3}$ Moo Hyun Kim, ${ }^{1,2 *}$ Kai Song ${ }^{1,2}$ Long Zhe Guo, ${ }^{3}$ En Ze Jin, ${ }^{3}$ Sun Young Choi, ${ }^{4}$ Kwang Min Lee ${ }^{1,2}$ \\ 'Department of Cardiology, Dong-A University Hospital, Busan, Korea \\ ${ }^{2}$ Clinical Trial Center, Dong-A University Hospital, Busan, Korea \\ ${ }^{3}$ Department of Cardiology, The Fourth Affiliated Hospital of Harbin Medical University, Harbin, China \\ ${ }^{4}$ Department of Biomedical Laboratory Science, Daegu Health College, Daegu, Korea
}

Received: 9 March 2018 Revised: 10 May 2018

Accepted: 18 May 2018

*Corresponding author: Moo Hyun Kim, MD, FACC

Department of Cardiology, College of

Medicine, Dong-A University,

26 Daesingongwon-ro, Seo-gu

Busan 49201, Korea

Tel: $+82-51-240-2976$

Fax: +82-51-255-2177

E-mail:kimmh@dau.ac.kr
Copyright (C) Korean Society on Thrombosis and Hemostasis. All rights reserved.
Purpose: We sought to determine if the CYP4F2 gene could affect warfarin maintenance dosage in Korean patients with a variety of diseases. CYP4F2 was reported to affect warfarin dose, but it was controversial. Some papers showed that CYP4F2 genotype could affect warfarin stable dose to some extent. But other papers reported that CYP4F2 genotype did not affect warfarin dose.

Methods: We enrolled 101 patients treated with warfarin in our registry. Non-genetic factors (clinical characteristics, stable warfarin dose, INR, medication information) and CYP4F2 polymorphisms were assessed. The definition of warfarin stable dose was the amount of medication given to maintain the patient's INR within the target range throughout at least 3 consecutive laboratory measurements separated by at least 1 week. Each patient's target therapeutic INR range was determined by the clinicians according to the indication for warfarin treatment.

Results: In our study, average patient age was $64.0 \pm 11.9$ years. Females accounted for $52 \%$ of the sample. The average warfarin maintenance dose was $3.26 \pm 1.38(1-9) \mathrm{mg} /$ day. Compared with CYP4F2 wild type patients (GG), the patients carrying a CYP4F2 heterozygous variant (GA) or a CYP4F2 homozygous variant (AA) required higher warfarin dose. The mean warfarin dose in the patients with the CYP4F2 AA genotype was $4.1 \pm 1.9 \mathrm{mg} /$ day, while that for the patients with the CYP4F2 GA genotype was $3.3 \pm 1.3 \mathrm{mg} /$ day, and that for the patients with the CYP4F2 GG genotype was $3.0 \pm 1.2 \mathrm{mg} /$ day. The difference among them was significant $(P=0.038)$.

Conclusion: CYP4F2 polymorphisms statistically influenced the stability of warfarin maintenance dosage in Korean patients with a variety of diseases.

Keywords: CYP4F2 polymorphisms, Warfarin dose, Korean

\section{Introduction}

Warfarin, as a common oral anticoagulant, is used to prevent and treat thromboembolic diseases such as atrial fibrillation (AF), heart valve replacement, deep venous thrombosis, and pulmonary embolism. ${ }^{1}$ Warfarin has many disadvantages such as narrow therapeutic index and wide dose variation of interindividual response, and its stable dosage is influenced by a variety of factors. ${ }^{2}$ Thus, determining warfarin therapy is challenging.

Several studies have shown that genetic polymorphisms affect warfarin pharmacodynamics, especially CYP2C9 and vitamin K epoxide reductase complex subunit 1 (VKORC1). ${ }^{2,3}$ One study demonstrated that the VKORC1 genotype can explain about $27 \%$ of warfarin dose variation, and the CYP2C9 genotype can explain about $7 \%$ of the warfarin dose variation in Asian patients. ${ }^{4}$ Combining this with other non-genetic factors, VKORC1 and CYP2C9 in warfarin pharmacokinetics and pharmacodynamics account for approximately $50 \%$ of inter-individual warfarin dose variation. ${ }^{5}$ However, half of the variation sources are still unknown.

CYP4F2 is an enzyme that can catalyze multiple reactions and affect warfarin dose. CYP4F2 is a primary liver vitamin K1 oxidase that catalyzes the metabolism of vitamin K1 to hydroxy-vitamin K1 and removes vitamin $\mathrm{K}$ from the vitamin $\mathrm{K}$ cycle, which can lead to less vitamin $\mathrm{K}$ available for clotting factor activation. ${ }^{6}$ The physiologic role of CYP4F2 in the vitamin $\mathrm{K}$ /warfarin pathway is controversial. Some studies have shown that the CYP4F2 genotype can affect warfarin dose. Compared to wild-type patients, patients with CYP4F2 variants need higher warfarin dose. ${ }^{7-10}$ But some papers reported that the CYP4F2 genotype did not affect warfarin dose. ${ }^{11-14}$ In addition, the CYP4F2 gene influence on warfarin dosage has not been frequently tested in the Korean population. Therefore, we sought to determine if CYP4F2 could affect warfarin dosage in Korean patients with a variety of diseases.

\section{Methods}

Study design and patient enrollment

In this observational study, we enrolled 101 Korean patients from the Hospital of Dong-A University between July 2015 and Jan 2018. All patients provided informed consent prior to entering the study. Clinical characteristics, stable warfarin dose, INR, and CYP4F2 genotype were assessed. We collected the clinical data by reviewing 
electronic and paper medical records, directly inquiring during regularly scheduled clinic visits, and telephone counseling. The clinical data comprised gender, age, height, weight, habits such as smoking and alcohol, target INR, concomitant diseases, combined medications, left ventricular ejection fraction (LVEF), and warfarin stable dosage. The concomitant diseases were AF, thromboembolic disease, heart valve disease, cerebral infarction, coronary heart failure, hypertension, diabetes mellitus (DM), and hyperlipidemia (HLP). The combined medications were $\beta$-blocker, amiodarone, angiotensin receptor blocker (ARB), angiotensin-converting enzyme inhibitors (ACEI), aspirin, clopidogrel, statin, calcium channel blocker (CCB), diuretics, and nitrates. We defined body mass index (BMI) as weight $(\mathrm{kg})$ divided by height $(\mathrm{m})$ squared and body surface area (BSA) as $\{[\text { Height }(\mathrm{cm}) \times \text { Weight }(\mathrm{kg})] / 3,600\}^{1 / 2}$. The stable dose of warfarin was defined as the maintenance dose at which a patient's INR was within the target range for at least 3 consecutive laboratory measurements separated by at least 1 week. ${ }^{2}$ The inclusion criteria were patients who were 20-80 years with body weight above $50 \mathrm{~kg}$ treated with warfarin. The exclusion criteria were history of chronic liver failure, treatment with other anticoagulant medication, active malignancy, renal insufficiency (creatinine $>2.0 \mathrm{mg} / \mathrm{dL}$ or eGFR $<$ $45 \mathrm{~mL} / \mathrm{min}$ ), and short life expectancy ( $<1$ year).

\section{Genotyping}

Genomic DNA from the patients was isolated from peripheral whole blood using the QIAamp DNA Blood Mini Kit (Qiagen GmbH, Hilden, Germany) according to the protocol of the manufacturer. Genotyping was conducted using $\mathrm{SNaPshot} \mathrm{assays.} \mathrm{The} \mathrm{samples} \mathrm{were}$ analyzed using an ABI-Prism 3130 genetic analyzer (Applied Biosystems, CA, USA). The SNaPshot results were analyzed by GeneMapper $^{\circledR}$ version 3.7 software (Applied Biosystems, CA, USA). The genotype classifications were CYP4F2 GG, CYP4F2 AG, and CYP4F2 AA.

\section{Statistical analysis}

Categorical variables were presented as percentage, while continuous variables were presented as mean \pm standard deviation. For baseline, Pearson's Chi-square test or Fisher's Exact Test was performed where appropriate. The correlations between the variables and warfarin stable dose were analyzed by independent samples T test. Oneway ANOVA test was performed for comparing the association between warfarin stable dose and genotype of CYP4F2. Multiple linear regression was performed to model the relationships of dose with other measuring variables and was used to develop a prediction algorithm for warfarin stable dose. In this statistical model, the stepwise selection method was applied to identify significant covariates of the clinical characteristics. Survival data were estimated according to multivariate Cox hazard regression analyses, and the differences between groups were compared with the log-rank test. All statistical analysis was carried out using SPSS software 20.0 (SPSS, Inc., Chicago, IL, USA) with the level of significance set at $P<0.05$.

\section{Results}

Clinical and general characteristics of studied patients

Table 1 summarizes clinical and demographic characteristics of studied patients. The mean age was $64.0 \pm 11.9$ years. Females comprised $52 \%$ of the population. The mean percentage of time in the therapeutic range (TTR) was $52.0 \pm 17.3 \%$ in the trial. The mean clinical maintenance warfarin dose was $3.26 \pm 1.38$ (1-9) mg/day. Main in-
Table 1. Baseline clinical characteristics

\begin{tabular}{|c|c|c|c|}
\hline Total $(n=101)$ & $\begin{array}{l}\text { Number of } \\
\text { patients (\%) }\end{array}$ & $\begin{array}{l}\text { Warfarin dose } \\
\text { (mg/day) }\end{array}$ & $P$-value \\
\hline Female & $53(52)$ & $3.2 \pm 1.9$ & 0.845 \\
\hline Age $\geq 70$ (year) & 37 (37) & $2.9 \pm 1.0$ & 0.013 \\
\hline$<70$ & $64(63)$ & $3.4 \pm 1.5$ & \\
\hline $\mathrm{BMI} \geq 23\left(\mathrm{~kg} / \mathrm{m}^{2}\right)$ & $59(58)$ & $3.5 \pm 1.5$ & 0.025 \\
\hline$<23$ & $42(42)$ & $2.9 \pm 1.1$ & \\
\hline $\begin{array}{l}\text { BSA (Male } \geq 1.9 \mathrm{~m}^{2} \text { or } \\
\left.\text { Female } \geq 1.6 \mathrm{~m}^{2}\right)\end{array}$ & $34(34)$ & $3.8 \pm 1.4$ & 0.004 \\
\hline Smoking & $14(14)$ & $3.0 \pm 1.1$ & 0.483 \\
\hline Alcohol & $13(13)$ & $3.5 \pm 1.3$ & 0.501 \\
\hline LVEF $\geq 50(\%)$ & $70(72)$ & $3.4 \pm 1.5$ & 0.203 \\
\hline$<50$ & $27(28)$ & $3.0 \pm 1.1$ & \\
\hline \multicolumn{4}{|l|}{ Disease } \\
\hline $\mathrm{AF}$ & $84(83)$ & $3.0 \pm 1.2$ & 0.002 \\
\hline Thromboembolic disease & $8(8)$ & $3.2 \pm 1.1$ & 0.939 \\
\hline Heart valve disease & $9(9)$ & $3.7 \pm 1.6$ & 0.082 \\
\hline Cerebral infarction & $24(24)$ & $3.3 \pm 1.2$ & 0.961 \\
\hline Coronary heart failure & $31(31)$ & $3.1 \pm 1.3$ & 0.434 \\
\hline Hypertension & $40(40)$ & $3.2 \pm 1.1$ & 0.786 \\
\hline Diabetic mellitus & $20(20)$ & $3.0 \pm 1.7$ & 0.351 \\
\hline Hyperlipidemia & $8(8)$ & $2.4 \pm 0.7$ & 0.079 \\
\hline \multicolumn{4}{|l|}{ Medications } \\
\hline$\beta$-Blocker & $13(13)$ & $3.6 \pm 1.2$ & 0.294 \\
\hline Amiodarone & $33(33)$ & $2.8 \pm 1.1$ & 0.010 \\
\hline ARB & $17(17)$ & $3.4 \pm 1.2$ & 0.704 \\
\hline ACEI & $12(12)$ & $3.0 \pm 1.2$ & 0.527 \\
\hline Aspirin & $15(15)$ & $3.1 \pm 1.0$ & 0.704 \\
\hline Clopidogrel & $16(16)$ & $3.2 \pm 1.1$ & 0.939 \\
\hline Statin & $18(18)$ & $3.2 \pm 1.3$ & 0.850 \\
\hline CCB & $21(21)$ & $3.2 \pm 1.2$ & 0.716 \\
\hline Diuretics & $68(67)$ & $3.1 \pm 1.3$ & 0.041 \\
\hline Nitrates & $11(11)$ & $3.5 \pm 1.2$ & 0.503 \\
\hline
\end{tabular}

Data are presented as mean $\pm \mathrm{SD}$, median (interquartile range), or number (\%). $\mathrm{BMI}$, body mass index; BSA, body surface area; LVEF, left ventricular ejection fraction; $A F$, atrial fibrillation; $A R B$, angiotensin receptor blocker; $A C E l$, angiotensin-converting enzyme inhibitors; CCB, calcium channel blocker

dications of treatment were atrial fibrillation (83\%), pulmonary thromboembolic disease/deep vein thrombosis $(8 \%)$, and valvular heart disease and/or valve replacement $(9 \%)$. Other associated diseases were cerebral infarction (24\%), coronary heart failure (31\%), hypertension (40\%), diabetes mellitus (DM) $(20 \%)$, and hyperlipidemia (HLP) (8\%). One-third of the patients $(33 \%)$ reported receiving amiodarone. More patients $(68,67 \%)$ were treated with diuretics. The patients with higher BMI or higher BSA required significantly higher warfarin dose $(P=0.025, P=0.004$, respectively). The patients diagnosed with $\mathrm{AF}$ had significantly lower warfarin dose $(P=0.002)$. Amiodarone and diuretics significantly reduced warfarin dose requirements $(P=0.010, P=0.041$, respectively). There were no significant differences for the other clinical characteristics.

Genotype frequency of CYP4F2

For CYP4F2 18000G > A (rs2108622), 46 patients (45.5\%) were 
Table 2. CYP4F2 genetic frequency

\begin{tabular}{lccrcc}
\hline Gene & SNP & Allele & $\begin{array}{r}\text { Patients, } \\
\text { No }(\%)\end{array}$ & Genotype & $\begin{array}{c}\text { Patients, } \\
\text { No }(\%)\end{array}$ \\
\hline CYP4F2 & $18000 \mathrm{G}>\mathrm{A}$ & $\mathrm{G}$ & $136(67.3)$ & $\mathrm{GG}$ & $46(45.5)$ \\
& $($ rs210862) & $\mathrm{A}$ & $66(32.7)$ & $\mathrm{AG}$ & $44(43.6)$ \\
& & & & AA & $11(10.9)$ \\
\hline
\end{tabular}

Data are presented as number (\%).

SNP, single nucleotide polymorphism.

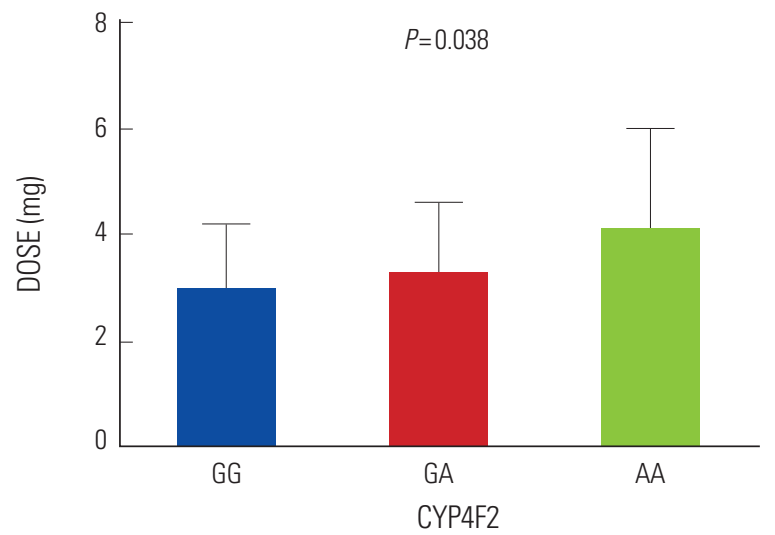

Fig. 1. Influence of CYP4F2 Genotype on Warfarin Dose.

homozygous for the wild $\mathrm{G}$ allele, 44 patients (43.6\%) were heterozygous for the wild A allele, and 11 (10.9\%) patients were homozygous for the variant A allele. CYP4F2 allele frequencies were $67.3 \%$ for the $\mathrm{G}$ allele and $32.7 \%$ for the A allele (Table 2).

Effect of CYP4F2 18000G $>$ A genotype on warfarin stable dose As shown in Fig. 1, the mean warfarin dose was higher in patients with the CYP4F2 AA genotype ( $4.1 \pm 1.9 \mathrm{mg}$ per day) compared with that of the GA $(3.3 \pm 1.3 \mathrm{mg} /$ day $)$ or GG $(3.0 \pm 1.2 \mathrm{mg} /$ day $)$ genotype. A significant association was observed between warfarin dose and $18000 \mathrm{G}>$ A of CYP4F2 $(P=0.038)$.

Clinical factors to determine warfarin dose

From multiple linear regression models, 5 variables were selected as significant factors that influenced the warfarin stable dose: age, BSA, amiodarone, diuretics, and CYP4F2 genotype. The results are presented in Table 3 and Table 4. Sex, smoking, alcohol use, concomitant disease, concurrent medications (except for amiodarone and diuretics), and LVEF were eliminated as predictors because of their weak association with warfarin dose requirements. The predictive contribution of the 5 variables to variability was $33.3 \%$ in our model for daily warfarin maintenance dosing.

The equation was: warfarin maintenance dose $(\mathrm{mg} / \mathrm{day})=4.387+$ $1.053 *$ BSA- $0.631 *$ Amiodarone $+0.430 *$ CYP4F2-0.335*Diuretics$0.043 *$ Age

The coding was as follows: CYP4F2 $18000 \mathrm{G}>\mathrm{A}$ genotype: input 0 for GG, 1 for AG, and 2 for AA. Amiodarone or diuretics was coded as 1 if present and 0 if absent.

\section{Discussion}

CYP4F2 is a vitamin K cycle-related enzyme that metabolizes vita-
Table 3. Univariate factors affecting warfarin dose

\begin{tabular}{lcccc}
\hline Variables & $\mathrm{R}^{2}$ & $\beta$ & $\begin{array}{c}\text { Adjusted for } \\
\mathrm{R}^{2} \text { model }\end{array}$ & $P$-value \\
\hline Intercept & & & & \\
Age & 0.185 & -0.050 & 0.177 & $<0.001$ \\
CYP4F2 & 0.060 & 0.505 & 0.051 & 0.013 \\
Amiodarone & 0.055 & -0.688 & 0.046 & 0.018 \\
BSA & 0.097 & 2.131 & 0.088 & 0.001 \\
Diuretics & 0.041 & -0.595 & 0.032 & 0.041 \\
\hline
\end{tabular}

Table 4. Multivariate factors affecting warfarin dose

\begin{tabular}{lrrrrrr}
\hline & B & Std. Error & $P$-value & \multicolumn{2}{c}{ Cl 95\% } & \multicolumn{1}{c}{$\beta$} \\
\hline Age & -0.043 & 0.010 & 0.000 & -0.062 & -0.023 & -0.369 \\
Amiodarone & -0.631 & 0.246 & 0.012 & -1.119 & -0.144 & -0.216 \\
CYP4F2 & 0.430 & 0.174 & 0.015 & 0.085 & 0.776 & 0.209 \\
BSA & 1.053 & 0.638 & 0.102 & -0.214 & 2.321 & 0.154 \\
Diuretics & -0.335 & 0.267 & 0.213 & -0.864 & 0.195 & -0.115 \\
Constant & 4.387 & 1.425 & 0.003 & 1.558 & 7.217 & \\
R $^{2}$ & 0.333 & & & & & \\
Adjusted $R^{2}$ & 0.298 & & & & & \\
$P$ & 0.000 & & & & & \\
\hline
\end{tabular}

$\min \mathrm{K}$ to hydroxyvitamin $\mathrm{K}$. This leads to less vitamin $\mathrm{K}$ available for clotting factor activation. The activity of CYP4F2 is reduced in individuals with the CYP4F2 Val433Met SNP(rs2108622, c.1297G>A), resulting in a reduced capacity to metabolize vitamin $\mathrm{K}$ and a greater amount of vitamin $\mathrm{K}$ to utilize. ${ }^{6}$ In addition, CYP4F2 is known to be primarily responsible for metabolizing arachidonic acid to 20-hydroxyeicosatetraenoic acid (20- HETE), which is a potent cerebral artery vasoconstrictor. ${ }^{3}$ Many studies have revealed that CYP4F2 gene polymorphisms might be associated with the risk of incident ischemic stroke and myocardial infarction. ${ }^{15,16}$

The physiologic role of CYP4F2 in the vitamin K/warfarin pathway is controversial. Most papers posited that CYP4F2 genotype could affect warfarin stable dose to some extent. Julie A et al. illustrated that both Caucasians and Asians required higher warfarin dose with CYP4F2 varients. ${ }^{6}$ Caldwell et al. shown that an exonic polymorphism in CYP4F2 was related to the difference of warfarin maintenance dose in a genome-wide association study (GWAS) in Caucasian patients. ${ }^{7}$ This paper pointed out higher warfarin dose requirements with the CYP4F2 mutant genotype in Asians. ${ }^{8}$ CYP4F2 polymorphism also significantly influenced warfarin dosing variability in the Italian population. ${ }^{9}$ In 2010 , Cha et al. first established the association of CYP4F2 with warfarin dose in the Japanese. ${ }^{10}$

However, some papers showed opposing results. In a total of 207 Egyptian patients, although a trend for dose differences by genotype was observed, there was no significant association between CYP4F2 polymorphism and warfarin dose requirement $(P=0.314) .{ }^{11}$ Perini et al. also observed no association between CYP4F2 genotype and warfarin dose requirement in 370 Brazilian patients. ${ }^{12}$ In 2011, a Korean group reported that the daily warfarin doses of patients carrying the TT genotype were higher than those of patients carrying the CC genotype $(3.5 \pm 2.5$ vs. $3.0 \pm 1.5 \mathrm{mg} /$ day, $P=0.0501) .{ }^{13} \mathrm{Re}-$ cently, a study demonstrated that the genotype and alleles of CYP4F2 did not show significant association with the maintenance 
dose requirements of acenocoumarol in Indian patients with cardiac valve replacement. ${ }^{14}$ In our registry, the mean warfarin dose was higher in the patients with the CYP4F2 AA genotype ( $4.1 \pm 1.9 \mathrm{mg}$ / day) compared with that of the AG (3.3 $\pm 1.3 \mathrm{mg} /$ day) or GG (3.0 \pm $1.2 \mathrm{mg} /$ day) genotype. A significant association was observed between warfarin dose and CYP4F2 genotype $(P=0.038)$. We confirmed that CYP4F2 genotype significantly affected warfarin stable dose. In our study, $89.1 \%$ patients had either homozygous or heterozygous genotype for CYP4F2 (GG or GA), while 10.9\% patients had homozygous genotype (AA), which is similar to a previous study in a Korean population. ${ }^{17}$

Our study can explain $33.3 \%$ of the variance in warfarin dose based on genetic polymorphisms of CYP4F2 and non-genetic indicators of age, BMI/BSA, amiodarone, and diuretics. Although CYP4F2 genotype mildly influenced warfarin dosage, including this factor in our algorithm can be used to improve prediction of warfarin stable dose.

In several guidelines for the treatment of AF in Western patients, ${ }^{2,18}$ an INR of PT between 2.0 and 3.0 was recommended for patients with non-valvular atrial fibrillation (NVAF), regardless of age. In contrast, Japanese guidelines recommend a slightly lower INR of 1.6-2.6 for elderly ( $\geq 70$ years) patients. ${ }^{19}$ Studies of Asian patients have chosen this guideline as their target INR. ${ }^{20-22}$ We also chose this as our target INR.
Limitations

Our study had a limited number of patients, and we only confirmed the influence of CYP4F2 gene on warfarin dose. In our algorithm, we did not include other genetic factors such as VKORC1 or CYP2C9. In the future, we will collect more factors to derive the algorithm to predict warfarin maintenance dose in Korean patients with a variety of diseases.

\section{Conclusion}

CYP4F2 polymorphism statistically influenced the stability of warfarin maintenance dosage in Korean patients with various diseases.

\section{Conflicts of interest}

Dr. Kim $\mathrm{MH}$ received a research grant from Bayer Co. The other authors did not have any conflict.

\section{Acknowledgments}

This research was supported by a grant from the Korea Health Technology R\&D Project through the Korea Clinical Trials Global Initiative (KCGI), funded by the Ministry of Health \& Welfare (No. HI14C1731), and by the National Research Foundation of Korea (NRF) (No. 2015R1D1A1A09057025), Republic of Korea.

\section{References}

1. Lee MTM, Klein TE. Pharmacogenetics of warfarin challenges and opportunities. J Hum Genet 2013;58: 334-8.

2. Anderson JL, Horne BD, Stevens SM, Woller SC, Samuelson KM, Mansfield JW, et al. A Randomized and clinical effectiveness trial comparing two pharmacogenetic algorithms and standard care for individualizing warfarin dosing: CoumaGen-II. Circulation 2012;125: 1997-2005.

3. Lee KE, Chang BC, Kim HO, Yoon IK, Lee NR, Park $\mathrm{HY}$, et al. Effects of CYP4F2 gene polymorphisms on warfarin clearance and sensitivity in Korean patients with mechanical cardiac valves. Ther Drug Monit 2012; 34:275-82.

4. Chen J, Shao L, Gong L, Luo F, Wang J, Shi Y, et al. A pharmacogenetics-based warfarin maintenance dosing algorithm from Northern Chinese patients. PLoS One 2014;9:e105250.

5. Scott SA, Khasawneh R, Peter I, Kornreich R, Desnick RJ. Combined CYP2C9, VKORC1 and CYP4F2 frequencies among racial and ethnic groups. Pharmacogenomics 2010;11:781-91

6. Johnson JA, Cavallari LH. Pharmacogenetics and cardiovascular disease - implications for personalized medicine. Pharmacol Rev 2013;65:987-1009.

7. Caldwell MD, Awad T, Johnson JA, Gage BF, Falkowski M, Gardina P, et al. CYP4F2 genetic variant alters required warfarin dose. Blood 2008; 111:4106-12.

8. Wei M, Ye F, Xie D, Zhu Y, Zhu J, Tao Y, et al. A new algorithm to predict warfarin dose from polymorphisms of CYP4F2, CYP2C9 and VKORC1 and clinical variables: derivation in Han Chinese patients with non valvular atrial fibrillation. Thromb Haemost 2012;108:108391.

9. Borgiani P, Ciccacci C, Forte V, Sirianni E, Novelli L, Bramanti P, et al. CYP4F2 genetic variant (rs2108622) significantly contributes to warfarin dosing variability in the Italian population. Pharmacogenomics 2009;10: 261-6.

10. Cha PC, Mushiroda T, Takahashi A, Kubo M, Minam S, Kamatani N, et al. Genome-wide association study identifies genetic determinants of warfarin responsiveness for Japanese. Hum Mol Genet 2010;19:4735-44.

11. Shahin MH, Khalifa SI, Gong Y, Hammad LN, Sallam MT, El Shafey M, et al. Genetic and nongenetic factors associated with warfarin dose requirements in Egyptian patients. Pharmacogenet Genomics 2011;21:130-5.

12. Perini J, Struchiner C, Silva-Assunção E, Suarez-Kurtz G. Impact of CYP4F2 rs2108622 on the stable warfarin dose in an admixed patient cohort. Clin Pharmacol Ther 2010;87:417-20.

13. Choi JR, Kim JO, Kang DR, Yoon SA, Shin JY, Zhang $\mathrm{X}$, et al. Proposal of pharmacogenetics-based warfarin dosing algorithm in Korean patients. J Hum Genet 2011; 56:290-5.

14. Rathore SS, Agarwal SK, Pande S, Singh SK, Mittal T, Mittal B. CYP4F2 1347 G>A \& GGCX 12970 C $>$ G polymorphisms: frequency in north Indians \& their effect on dosing of acenocoumarol oral anticoagulant. Indian J Med Res 2014;139:572-8.

15. Fava C, Montagnana M, Almgren P, Rosberg L, Lippi
G, Hedblad B, et al. The V433M variant of the CYP4F2 is associated with ischemic stroke in male Swedes beyond its effect on blood pressure. Hypertension 2008;52 373-80.

16. Fu Z, Nakayama T, Sato N, Izumi Y, Kasamaki Y, Shindo A, et al. A haplotype of the CYP4F2 gene associated with myocardial infarction in Japanese men. Mol Genet Metab 2009;96:145-7.

17. An SH, Chang BC, Lee KE, Gwak HS. Influence of UDP-Glucuronosyltransferase Polymorphisms on Stable Warfarin Doses in Patients with Mechanical Cardiac Valves. Cardiovasc Ther 2015;33:324-8.

18. Kirchhof P, Benussi S, Kotecha D, Ahlsson A, Atar D, Casadei B, et al. 2016 ESC Guidelines for the management of atrial fibrillation developed in collaboration with EACTS. Europace 2016; 18:1609-78.

19. Group JJW. Guidelines for pharmacotherapy of atrial fibrillation (JCS 2013). Circ J.2014;78:1997-2021.

20. Kodani E, Atarashi H, Inoue H, Okumura K, Yamashita T, Origasa H. Secondary prevention of stroke with warfarin in patients with nonvalvular atrial fibrillation: subanalysis of the J-RHYTHM Registry. J Stroke Cerebrovasc Dis 2016;25:585-99.

21. Kodani E, Atarashi H, Inoue H, Okumura K, Yamashita $T$, Origasa $H$, et al. Use of warfarin in elderly patients with non-valvular atrial fibrillation-subanalysis of the J-RHYTHM registry. Circ J 2015;79:2345-52.

22. Hirano T, Kaneko H, Mishina S, Wang F, Morita S. Suboptimal anticoagulant management in Japanese patients with nonvalvular atrial fibrillation receiving warfarin for stroke prevention. J Stroke Cerebrovasc Dis 2017; 26:2102-10 